\title{
VIAJES Y MEMORIA: LAS CIENCIAS EN ESPAÑA ANTES Y DESPUÉS DE LA GUERRA CIVIL*
}

\author{
María Jesús Santesmases \\ Departamento de Ciencia, Tecnología y Sociedad. Instituto de Filosofía, CSIC
}

\section{RESUMEN}

Este artículo repasa la influencia de la Junta para Ampliación de Estudios y el efecto de la política de pensiones en el extranjero en la trayectoria del Consejo Superior de Investigaciones Científicas. Se proponen el viaje de los pensionados de la JAE como fuente de saber científico y de sus prácticas. Se sugiere que la memoria institucional, como la de las ideas, no se borra en guerras civiles y dictaduras, por represoras que sean, que hay genealogía también de las prácticas de las ciencias y en la formación experimental a lo largo del siglo xx en España.

PALABRAS CLAVE: Junta para la Ampliación de Estudios, Consejo Superior de Investigaciones Científicas, práctica científica en España, memoria institucional.

\section{TRAVELS AND MEMORY: THE SCIENCES IN SPAIN BEFORE AND AFTER THE CIVIL WAR}

\section{ABSTRACT}

This essay revisits the influence of the Junta para Ampliación de Estudios (JAE), the effect in the trajectory of the Consejo Superior de Investigaciones Científicas of JAE grants and scholarships policy for Spanish young graduates to study abroad. It proposes grantee's travel as a source of knowledge and its practices. It develops the argument that institutional memory, as that of ideas, is not blurred by either a civil war or a dictatorship, repressive as it was. It also suggests genealogy of scientific practices and training during the $20^{\text {th }}$ century in Spain.

KEY WORDS: Junta para la Ampliación de Estudios, Consejo Superior de Investigaciones Científicas, scientific practice, institutional memory.

Cien años después de la creación de la Junta para Ampliación de Estudios e Investigaciones Científicas (JAE) empezamos a comprender y a debatir sobre el papel que ha desempeñado la primera iniciativa estatal de promoción de la

* Este artículo forma parte de los trabajos incluidos en un proyecto de Investigación (HUM2006-04939/Fiso) subvencionado por el Ministerio de Educación y Ciencia. 
investigación en la España contemporánea ${ }^{1}$. El papel jugado por José Castillejo, por el ideario krausista y por la élite cultural que se articulaba alrededor de las iniciativas tomadas desde la Institución Libre de Enseñanza se conoce bien. También se ha reconstruido la gestación del Instituto Nacional de Física y Química, la presencia de científicas en él, de la Misión Biológica de Galicia y otros laboratorios de biología, de los trabajos de genetistas ilustres, del laboratorio de fisiología como centro de investigación dedicado a introducir a estudiantes de Medicina en la investigación y en el trabajo experimental ${ }^{2}$.

Toda esa recuperación certifica naufragios y supervivencias, recoge cambios de código y, vista desde la época que le siguió, la dictadura de Franco, arroja los silencios que siguieron y la elocuencia verosímil de historias que buscan rastros, tratan de rescatar algunos orígenes o al menos la procedencia de lo que quedaría por surgir. El repaso historiográfico emerge teñido de lina-

1 Para una historiografía colectiva sobre la Junta para la Ampliación de Estudios, véanse los trabajos primeros recogidos en LAPORTA, F., J. SolAnA, Ruíz Miguel, A, ZAPATERO, V. y RODRÍGUEZ DE LECEA, T. (1987) La Junta para Ampliación de Estudios e Investigaciones Cientificas (1907-1936) Arbor; $1^{\text {a }}$ parte: 126 (493), 17-87; $2^{a}$ parte: 127 (499), 9-37; y SÁNCHEZ Ron, J. M. (coord.)(1988), 1907-1987 La Junta para Ampliación de Estudios e Investigaciones Científicas 80 años después. Madrid: CSIC, 1988a, 2 vols.; así como el reciente monográfico del Boletín de la Institución Libre de Enseñanza, En el centenario de la Junta para Ampliación de Estudios (1907-2007), publicado como número doble 63-64 en 2006. Una propuesta historiográfica que se ocupa de forma fragmentada de herencias y discontinuidades entre la JAE y el Consejo Superior de Investigaciones Científicas, creado en 1939, está en el volumen conmemorativo compilado por PUIG-SAMPER, M. Á. (ed.) (2007), Tiempos de investigación. JAE-CSIC cien años de ciencia en España, Madrid, CSIC.

2 Sobre el Instituto de Física y Química, véase GLICK, T. F. (1988), «La Fundación Rockefeller en España: Augustus Trownbridge y las negociaciones para el Instituto Nacional de Física y Química». En SÁnChez RoN, J. M. (coord.)(1988), 1907-1987 La Junta para Ampliación de Estudios e Investigaciones Científicas 80 años después. Madrid: CSIC, pp. 281-300. Magallón PortolÉs, C. (1998), Pioneras españolas en las ciencias. Las mujeres del Instituto Nacional de Física y Química. CSIC, Madrid. BARATAS, Alfredo (1997), Introducción y desarrollo de la biología experimental en España (1868-1936). Madrid: CSIC. PINAR, S. (2002), "The emergence of modern genetics in Spain and the effects of the Spanish civil war», Journal of the History of Biology 35: 111-148; Ibid (2002), «La vertiente histologica de José Fernández Nonídez, introducción de la teoría mendeliano-cromosómica en España», Asclepio, 54, 3-18; PINAR, S. (2003), «La genética española en la primera mitad del siglo xx». En CANDEla, M. (ed.), Los orígenes de la genética en España, Madrid, Sociedad Estatal de Conmemoraciones Culturales; y el reciente libro de Delgado, I. (2007), El descubrimiento de los cromosomas sexuales, Madrid, CSIC, esp. el capítulo 10. BARONA, J. L. (1990), La doctrina y el laboratorio. Fisiología y experimentación en la sociedad española del siglo XIX, Madrid, CSIC. 
jes y estirpes, de gentes y de instituciones, de normas y de prácticas. La guerra civil y la dictadura, con sus maneras demoledoras y reconstituyentes, no parecen haber borrado la memoria.

La historiografía muestra un conjunto de actividades científicas, de construcción de modos de trabajo investigadores, de códigos que se tomaron como propios de la práctica científica. Los usos propios de la adquisición de conocimiento y de la práctica experimental pasaban, en primer lugar, por bibliotecas actualizadas, revistas extranjeras leídas y entendidas, pero, sobre todo, por viajes a otros países como parte de la formación científica.

La creación de la JAE generó debates, especialmente en una universidad que tenía pendientes reformas y apoyo presupuestario ${ }^{3}$. Pero había precedentes en Europa de centros nacionales de investigación que se creaban fuera de las universidades, de organismos que suplían sus carencias fuera de las paredes de esos templos del deber de origen medieval y reciclados por la Ilustración, aunque tuviera este caso español una inspiración singular. Resulta verosímil buscar rastros en esos organismos cuya creación precede a la de la Junta, pues toman formas que recuerdan las que se hicieron propias del nuevo organismo español.

En este artículo he querido regresar al asunto de las huellas que la JAE dejó en el medio plazo a través del repaso de algunas normas, ideas y prácticas que se conservaron tras la guerra civil y pese a la dureza de la dictadura de Franco.

\section{VIAJES PARA EL APRENDIZAJE Y EL DESARROLLO}

La vía elegida por la JAE parece, vista desde hoy, específica y autóctona si se la compara con el entorno geográfico y político en el que surgió ${ }^{4}$. Recogió influencias extranjeras, por un lado, y se creó para afrontar carencias españolas concretas, por el otro. Al afrontar esas carencias, éstas toman nombre, se dotan de existencia singular y se convierten en conceptos cerrados, como las cajas negras.

3 SÁnchez Ron, J.M. (2006), «En defensa de la JAE. La España de 1900», Boletín de la Institución Libre de Enseñanza 63-64, 67-96.

4 Véase SÁnCHEZ Ron, J.M. (1988), «La Junta para Ampliación de Estudios, ochenta años después», en J. M. (coord.) (1988), 1907-1987 La Junta para Ampliación de Estudios e Investigaciones Científicas 80 años después. Madrid: CSIC, 1988, pp. 1-61; donde se recoge un estudio general de las pensiones solicitadas a la JAE y concedidas por esta. Véase también BARATAS, L. A. y FERNÁNDEZ PÉREZ, A., (1993), «Becas de ampliación de estudios en biología y ciencias básicas de la medicina en la España del primer tercio del siglo XX», Dynamis, 13, 247-263. 
El hecho de que las pensiones hayan sido una de las bases constitutivas de la JAE sugiere que las autoridades de ese tiempo y los inventores de este organismo de investigación detectaban la necesidad de completar la formación científica en el extranjero. Esa idea programática de crear un organismo para la investigación que se dedicara sobre todo a promover la «ampliación de estudios» en el extranjero sugiere el viaje como fuente esencial de conocimiento. Muchos habían aprendido antes así: extranjeros que viajaron por España, españoles en mudanza transatlántica y colonial. Viajes de idea y vuelta que generaron riqueza y piratería, leyenda y conocimiento que devino fiable. El viaje mismo se convirtió en fenómeno legendario a provocar: había que hacer posible más viaje y más leyenda. Y así salieron arquitectos, artistas, fisiólogos, químicas.

También que hay que considerar a esa España del siglo XIX que con tanta intención analiza Álvarez Junco, quien adjudica a las élites un papel principal tanto en la actualización y las posturas reformistas españolas como en el mantenimiento de algunas de las de signo más conservador. Unos valores sociales se mantenían en algunos grupos, y se desafiaban en otros, limitados esos grupos por situaciones políticas y económicas frágiles. Una ciudadanía con muy bajos niveles de alfabetización confiaba en conceptos como nación y religión, se atenía a las autoridades vigentes y a ideas, que, imperantes o en liza, resultaron en una nación española convulsa en lo político, pobre, de muy escaso desarrollo económico e industrial y que se sumaba a las tendencias en expansión en los países vecinos. El nacionalismo y la religión se usaron como razones y sinrazones, alternativamente, del desarrollo del país, según el periodo ${ }^{5}$. Pero el regusto amargo que se recuerda de escritores y pensadores del 98 contrasta con las actitudes más alegres desplegadas por el grupo que se articuló en torno a 1927.

Como gente que estudia la historia, compartimos el interés por la procedencia de las ideas que hicieron posible la dictadura. Y por sus armas, que quebraron tendencias prometedoras. Hay historiografía abundante para tratar de comprender, o al menos explicar, de dónde salió tanta pugna trágica por el poder político en España, contra libertades públicas y vaivenes ideológicos que evocan la vigencia del caciquismo. Esa es la cultura a la que pertenece la práctica investigadora en España, o al menos el medio del cual surge inmersa.

5 Álvarez Junco, J. (2001), Mater dolorosa: la idea de España en el siglo XIX, Madrid, Taurus. 


\section{VIAJES DE PRODUCTOS Y MANUALES DE MANEJO}

Una industrialización tardía, dependiente de máquinas, técnicas y manuales de uso fabricados en otros países y una geografía bien distinta a la del país inventor de la primera ola de la industrialización europea (Inglaterra) parecen haber caracterizado a la época que transita entre el siglo XIX y el XX en España, que es cuando se inicia la transformación de la producción de primaria (agrícola y ganadera) en secundaria (fabril) en todo Occidente. El desarrollo de la producción industrial al amparo de la máquina de vapor y de la extracción de carbón es un hito que no debe considerarse producto de un momento concreto, heroico o genial, sino de un proceso de transformaciones paulatinas del artesanado a la industria. Se generaban los excedentes que favorecían la exportación. Y la salida de los productos, su viaje, marcaba pautas que se conservan hoy como uno de los caracteres que permiten la supervivencia de los países, de sus economía y, también, de sus comunidades científicas, compuestas estas de gentes expertas en técnicas, fabricación y uso de instrumentos que no surgen del movimiento animal sino de la producción de energía. La revisión de Rosés (2006) y el pensamiento de Prados de la Escosura (1988) desde la historia económica e industrial son informativos y sugerentes al respecto ${ }^{6}$.

La compartimentación disciplinar de los estudios históricos tiene cautivas ideas y conceptos que no se intercambian entre especialista de distintas áreas de estudio. La historia de las ideas y de los acontecimientos políticos, como la historia social y del mercado de trabajo, cuenta con propuestas de las que aprendemos continuamente. Pero tenemos pendiente ese intercambio con otras disciplinas históricas, aunque a veces nos dejemos inspirar por las propuestas de historiografía variada.

Hay una idea común que se comparte: el viaje. Las personas y los productos salen de los lugares donde nacen y se fabrican, atraviesan fronteras y expanden su influencia. El viaje sería, por eso, además de productor de conocimiento - a este respecto la propuesta de Pimentel (2003) y de los autores que

6 RosÉs, J. R. (2003), «Why Isn't the Whole of Spain Industrializad. New Economic Geography and Early Industrialisation, 1797-1910», Journal of Economic History, 63, 9951022. Véanse también RosÉS, J. R. (2006), «La primera etapa de la industrialización»; en GonZÁlez EnCISO, A, y J.M. MATÉS BlANCO (coords.): Historia económica de España, Barcelona, Ariel, pp. 185-207; y PRAdOs DE LA EsCOSURA, L. (1988), De imperio a nación. Crecimiento y atraso económico en España (1780-1930), Madrid, Alianza. 
le inspiran es muy evocadora-, fuente de transformación ${ }^{7}$. Al viajar los productos, inicial y esencialmente la máquina de vapor y sus manuales de uso, se extiende la influencia de sus productores. Viajen o no físicamente con ellos, los inventores emprenden así también un viaje y, más que eso, la mudanza y el transporte generan riqueza industrial y económica. Con las máquinas, viajan las ideas: sobre cómo usarlas, su composición, y la aceptación, o no, de su proceso de funcionamiento como algo cerrado; devienen cajas negras de la técnica y el denominado desarrollo, cuyo logro pasa por el uso de estas, certificado por los éxitos acumulados por su manejo previo en otros lugares. El viaje se hace agencia, productor y generador de ideas, personaje de la historia. Como si del ferrocarril se tratara - Schumpeter ha analizado de forma preciosa al ferrocarril, el viajero del hierro y del carbón industriales, y su papel en lo que llamó ciclos económicos-, el viaje interviene en los procesos del saber y de las prácticas dadas por científicas y técnicas ${ }^{8}$.

Esos viajes de las máquinas y sus ideas asociadas pueden ser solo de ida; mientras que las gentes suelen regresan. La orografía del territorio, su paisaje, puede facilitar o dificultar el viaje, y hasta el regreso. Pero si hay estímulos y ayudas, este se emprende más frecuentemente que cuando los mecanismos son disuasorios: de ahí el éxito limitado pero de influencia en el largo plazo de la política de pensiones de la JAE. Lo interesante del viaje de las gentes, visto desde el país desde el que lo emprenden, es el regreso. Y lo es también el conjunto de mecanismos por los cuales se rearticula el hacer y el saber de cada cual al regreso: cómo se incorporan las ideas y las prácticas al lugar de donde se salió, cómo se adoptan nuevos códigos y se recodifican saberes previos.

Los resultados de la política de pensiones de la Junta están por evaluar con todo el detalle que los documentos disponibles merecerían. Algunos estudios hacen propuestas sobre su importancia. Hoy, cien años después de emprenderse aquella empresa de apariencia modesta pero extraordinariamente ambiciosa si se contempla inmersa en el medio que la hizo posible, se puede formular la pregunta sobre qué rastro dejó aquella estrategia viajante de la Junta en los usos y los mecanismos de promoción de la investigación en España.

7 Pimentel, J. (2003), Testigos del mundo. Ciencia, literatura y viajes en la Ilustración, Madrid, Marcial Pons.

8 SCHUMPETER, J.A. (1939), Busyness cycles: a theoretical historical and statistical analysis of the capitalist process, Nueva York, McGraw Hill. Una reciente traducción de Jordi Pascual, prologada por Fabián Estapé se ha publicado en 2002 como Ciclos económicos. Análisis teórico, histórico y estadístico del proceso capitalista, Zaragoza, Prensas Universitarias de Zaragoza. Sobre el ferrocarril en España, véase GómEZ MENDOZA, A (1989), Ferrocarril, industria y mercado de la modernización en España, Madrid, Espasa-Calpe. 
El factor limitante de esa influencia ha sido la guerra civil ${ }^{9}$. Porque impuso condiciones, especialmente por el triunfo de Franco y sus ejércitos, que restringieron las manifestaciones que pudo haber ejercido el conjunto de estrategias formadoras y reformadoras de la JAE. Las diferencias entre la España de antes y de después de la guerra civil darían una lista que rayaría en la caricatura si no fuera porque la España de la posguerra sería caricatura propia del humor de la clase más negra. Decir pobreza y decir aislamiento es simplificar, aunque no caricaturizar. Ambas características no dejan por su dramatismo de ser a su vez evocadoras de lo que pudo haber sido y no fue, de una nostalgia que se convierte ya en análisis de situación.

Ninguna nostalgia, ni la memoria familiar ni la historiografía, nublaría a estas alturas la vista sobre la historia y el peso de sus acontecimientos sobre el discurrir de las ciencias en España a lo largo del siglo xx. La guerra civil y la represión de la posguerra abrieron la brecha científica y técnica, porque la represión fue especialmente dura con los catedráticos y los organismos más productivos, porque la purga afectó a aquellos que se habían formado en un medio gobernado por otras normas. Había mucho que hacer, una larga distancia que salvar. Aquellos mecanismos por los cuales los gobiernos de la dictadura afrontaron el «nuevo orden» marcan el origen de la construcción de la legitimidad internacional del régimen político español, de la sociedad y de las políticas; de las comunidades profesionales expertas también. Finalmente la dictadura de Franco quebró otra ilusión (otra a añadir a la estudiada por Puerto Sarmiento, 1988$)^{10}$. La quiebra social, política, económica, es también quiebra científica, de saberes y prácticas cuya desaparición pareció haberse pretendido. Esa pretensión es elocuente en los primeros discursos sobre la ciencia que se dieron en España tras la guerra y de ella es himno testimonial la propia norma de creación del CSIC en $1939^{11}$.

9 Sobre la institucionalización de las ciencias durante la guerra civil, en el gobierno provisional de Franco en Burgos, véase MALET, A., (2007), «Las primeras décadas del CSIC. Investigación y ciencia para el franquismo»; en RoMERO, A., y SANTESMASES, M.J. (eds.), Cien años de politica científica en España, Madrid, Fundación BBVA (en revisión). Sobre la JAE en ese mismo momento, SÁNCHEZ Ron, J.M., 1999, «La guerra civil y la ciencia», en su Cincel, martillo y piedra, Madrid, Taurus, pp. 301-327.

10 Puerto SARmiento, J. (1988), La ilusión quebrada: botánica, sanidad y política científica en la España ilustrada, Barcelona, Serbal.

11 Una investigación pionera sobre la creación del CSIC y sus normas está en GONZÁLEZ Blasco, P (1980), El investigador científico en España, Madrid, CIS. 


\section{RECICLAJES LOCALES}

Una vez abierto, al amparo de las celebraciones centenarias de la JAE, y también las del Institut d'Estudis Catalans, el debate sobre si la JAE dejó herencias institucionales o fue explícitamente sofocada por las autoridades franquista, puede revisarse en qué se convirtió a aquel prometedor paisaje institucional estatal a favor del desarrollo científico e intelectual español ${ }^{12}$.

Los edificios patrimonio de la JAE y que pasaron a formar parte del CSIC tras su creación en 1939 son muestra física excelente de las intenciones y las decisiones tomadas por José Ibáñez Martín, primer ministro de Educación Nacional del primer gobierno de Franco tras la guerra civil. El patrimonio inmobiliario se gestiona y se recicla: se acomoda a los objetivos de las nuevas autoridades $^{13}$. El propio nombre del ministerio tiene significado: de instrucción pública a educación nacional. La tosquedad argumental de la norma de creación del CSIC en 1939 es también referencia obligada por lo explícito de sus intenciones restrictivas, cuando no coercitivas.

Lo que se habría intentado destruir, con éxito bastante aunque no fuera total, con la guerra y el gobierno de los vencedores liderados por Franco fue precisamente un discurso civil que incluía las ciencias, o al menos a la atención que atrajeron en ese momento de los intelectuales, autoridades y gente dispuesta a ejercer influencia política ${ }^{14}$. Para lo que interesa en esta ocasión, tras la guerra no solo las prácticas sociales y políticas cambian drásticamente; los discursos también lo hacen y en ocasiones más que las prácticas mismas. Rodríguez Ocaña (2001) da cuenta de una continuidad entre las administraciones republicana y franquista en la salud pública. En ambas detecta el mis-

12 Sobre el Institut d'Estudis Catalans, véanse BAlcells, A. y E. Pujol (2002), Història de l'Institut d'Estudis Catalans. Volumen 1, Catarroja, Barcelona, Afers- Institut d'Estudis Catalans; y BAlcells, A., S. IzQuierdo y E. Pujol (2007), Història de l'Institut d'Estudis Catalans. Volumen 2. Catarroja, Barcelona, Afers- Institut d'Estudis Catalans.

13 Guerrero, S. (2007), «La colina de los Chopos: un campus para la pedagogía y la ciencia modernas en la España del primer tercio del siglo XX», en PUIG-SAMPER, M.-Á. (ed.) (2007), Tiempos de investigación. JAE-CSIC cien años de ciencia en España. Madrid, CSIC, págs. 47-53; GUERRERO, S. (2007), «El conjunto urbano del CSIC en Madrid: retórica y experimentalismo en la arquitectura española del primer franquismo», en PUIG-SAMPER, M.-Á. (ed.) (2007), Tiempos de investigación. JAE-CSIC cien años de ciencia en España, Madrid, CSIC, pp. 285-291.

14 GLICK, T. F. (1994), «Ciencia, política y discurso civil en la España de Alfonso XIII». En GortázAr, G. (ed.), Nación y estado en la España liberal, Madrid, Fundación Ortega y Gasset - FAES, pp. 255-275. 
mo estilo hacia la fortaleza de la profesión de la salud pública como un dominio de actividad de carácter público, ligado a conceptos como el de higiene y a la formación en microbiología, que se incluye en el programa de los estudios de medicina. Esas circunstancias, sugiere, constituyen la base misma de modelo de atención sanitaria basado en la medicina hospitalaria con la sucesiva creación de los grandes hospitales por toda España y la implantación del seguro obligatorio de enfermedad. Y se trata de una trayectoria que se inicia en el primer tercio del siglo y se consolida en plena dictadura ${ }^{15}$.

La ruptura más grave que produjo la guerra fue la dictadura misma y sus prácticas. La represión al personal docente y científico de universidades y centros de investigación constituye una de las más trágicas ${ }^{16}$. Con repercusiones en el largo plazo, junto a ella se extiende y desarrolla una retórica ligada a ambiciones imperiales, basadas en conceptos militares de ley y orden. En el caso de la medicina, puede verse cómo la higiene física pasa a confundirse con la mental, y la población, en especial las mujeres y entre ellas, más interesadamente por la política de expansión demográfica, las madres, se considera por las autoridades como una ciudadanía inmadura que debe someterse a criterios profesionales ${ }^{17}$.

15 Rodríguez OcañA, E. (2001), «The Politics of Public Health in State-Managed Schemes of Healthcare in Spain (1940-1990)», en LöWY I.y J. KRIGE (eds.), Images of Disease: Science, Public Policy and Health in Post-war Europe, Luxembourg, Office for Official Publications of the European Communities, pp. 187-210.

16 Sobre la represión de profesores universitarios, véanse LóPEZ, S. (1996), «La investigación científica y técnica antes y después de la guerra civil», en GóMEZ MENDOZA, A. (coord.), Economía y sociedad en la España moderna y contemporánea, Madrid, Síntesis, pp. 265-276; sobre la que se dio en el instituto que dirigía Santiago Ramón y Cajal, SANTESMASES, María Jesús (1998), «El legado de Cajal frente a Albareda: las ciencias biológicas en los primeros años del CSIC y los orígenes del CIB», Arbor, núms. 631-632 (julio-agosto 1998), pp. 305-332. Un repaso sistemático por universidades está en ClARET, J. (2006), El atroz desmoche. La destrucción de la universidad española por el franquismo, Barcelona, Crítica; para el caso de la de Madrid, véase Otero CARVAJAL, L. E. (dir.)(2006), La destrucción de la ciencia en España. Depuración universitaria en el franquismo, Madrid, Editorial Complutense, 2006. Para una historia de la sociedad civil en plena represión franquista, CAzorLASÁnchez, A. (2000), Políticas de la Victoria. La consolidación del Nuevo Estado franquista (1938-1953), Madrid, Marcial Pons.

17 Jiménez Lucena, I, Ruiz Somavilla, M.J. y Castellanos Guerrero, J. (2002), «Un discurso sanitario para un proyecto político. La educación sanitaria en los medios de comunicación de masas durante el franquismo», Asclepio, 44, 201-218. Véase también JiMÉNEZ LUCENA, I. (1994). «El tifus exantemático de la posguerra española (1939-1943). El uso de una enfermedad colectiva en la legitimación del Nuevo Estado». Dynamis, 14, 185-198. 
Esas tendencias mantenidas pese a los drásticos cambios políticos han sido detectadas también por la historiografía de la industria. La historia industrial muestra empresas creadas en las primeras décadas del siglo XX que sobreviven a la guerra y crecen y expanden mercados tras ella. Bancos industriales y comerciales desarrollados al amparo del regreso de capitales desde Cuba también superan la crisis bélica, y en algunos casos firman pactos para repartirse sectores de negocio ${ }^{18}$. Los trabajos sobre la política autárquica que caracteriza la primera década de la dictadura de Franco han generado un debate sobre las razones del nacionalismo económico practicado en esa etapa del franquismo que ocupa hasta principios de la década de los $50^{19}$.

\section{MEMORIA PERSONAL E INSTITUCIONAL}

Visto desde hoy y con la historiografía a mano puede sugerirse que en medio del desenlace dramático de la guerra y el establecimiento de la dictadura, hubo algunos códigos que se mantuvieron. Como sobrevivieron bancos, procesos comerciales, relaciones exteriores para la exportación de cítricos, también lo hicieron los usos de la investigación y de la formación especializada ${ }^{20}$. El secretario general del CSIC José María Albareda, promovió la salida al extranjero de algunos jóvenes investigadores, que acudían a otros países en busca de una especialización que no podían alcanzar en España ${ }^{21}$. En esa acti-

18 Sobre el reparto del negocio bancario entre el Banco Hispano-Americano y el Banco Urquijo, véase GARcía Ruiz, José Luis y TORTElla, G. (1993), «Trayectorias divergentes, paralelas y convergentes: la historia del Banco Hispano Americano y del Banco Central, 1901-1965», en Asociación de Historia Económica, V Congreso de la Asociación de Historia Económica (Ponencias), San Sebastián, Universidad del País Vasco, pp. 339-355.

19 La bibliografía de historia industrial de España en el siglo xx no puede citarse aquí, por su riqueza y amplitud. Pueden mencionarse las revisiones de los efectos de la industrialización tardía de España en RosÉS, op.cit. (2006), y el influyente libro de PRADOS DE LA ESCOSURA (1988) junto a obras tan distintas a estas como la de CATALÁN, J. (1995), La economía española y la segunda guerra mundial, Barcelona, Ariel; así como el reciente volumen de NADAL, J. (dir) (2003), Atlas de la industrialización en España 1750-2000, Barcelona, Crítica-Fundación BBVA.

20 Sobre las relaciones comerciales extranjeras con España mantenidas desde el primer franquismo, véase GuIRAO, F. (1998), Spain and the Reconstruction of Western Europe 194557, Londres, MacMillan.

21 Esa idea está presente no solo en los estudios sobre su papel en el CSIC, sino en las biografías hagiográficas que se publicarían a su muerte. De los estudios, véanse SÁNCHEZ RoN, J. M. (1992), «Política científica e ideología: Albareda y los primeros años del Consejo 
tud puede verse el reconocimiento de Albareda a las carencias del medio que él mismo gobernaba; pero esa política debe considerarse también fruto de la formación que había recibido como pensionado de la JAE. De forma que, pese a rebelarse, al menos retóricamente, contra las ideas y modos de trabajo de la Junta, Albareda aplicó algunas de ellas 22 . Y en parte lo que sabía se debía a los viajes que había realizado con las pensiones y a lo que había aprendido en ellos.

Tampoco llegó a perderse la línea de pensamiento y práctica experimental que Santiago Ramón y Cajal había desarrollado con tanto éxito. La histología sufrió un desmoche atroz, como dijo Laín (1989) y recuerda ahora Claret (2006), pero hubo algunos trabajos que contribuyeron a carreras académicas en la neurofisiología, como el de Antonio Gallego con sus trabajos sobre la retina, que se produjeron a lo largo de la década de 1950 y hasta su retiro y las líneas de trabajo de las luego llamadas neurociencias empezarían a diversificarse pocas décadas después de liquidarse el pequeño pero productivo grupo de científicos discípulos de Cajal. Para la comunidad investigadora que construyó sus ambiciones científicas a lo largo de esa década en la que comenzó la recuperación española que fuera la de 1950 Cajal era un referente, y con su estela deben relacionarse los trabajo histológicos de las gentes que entonces trabajaban en el Instituto Cajal del CSIC por escasos que fueran los medios de los que disponían ${ }^{23}$.

Por lo tanto, además de la conciencia de las autoridades sobre la necesidad de salir al extranjero, estaba el rastro que Cajal y los éxitos internacionales que habían obtenido sus trabajos. Para cuando dos décadas después del fin de la guerra civil, Ochoa recibió el premio Nobel de Medicina, periodistas y algunos de sus amigos evocaron en la prensa al Nobel Cajal, y dejaron que Ochoa lo recordara también. Esa evocación sugiere genealogía, procedencia, inspiración. Si la primera política represora de la dictadura tuvo el gesto trá-

Superior de Investigaciones Científicas», Boletín de la Institución Libre de Enseñanza, n 14 , pp. 53-74; y SANTESMASES, M. J. (1998) «El legado de Cajal frente a Albareda», op. cit. Las biografías son las de GutiÉrRez Ríos, E. José María Albareda. Una época de la cultura española, Madrid, Magisterio Español; y CASTILlo GENZOR, Adolfo, y Mariano TOMEO LACRUÉ (1971), Albareda fue así, Madrid, CSIC.

22 Sobre la ideología de Albareda tras la guerra civil, véase SÁNCHEZ RON (1992)

23 Claret, Atroz desmoche, op. cit; Lain EnTRalgo, P. (1976), Descargo de conciencia, Barcelona, Seix Barral. SANTESMASES, M. J. (1999), Antibióticos en la autarquía: banca privada, industria farmacéutica, investigación cientifica y cultura liberal en España, 1940-1960, documento de trabajo, Madrid, Fundación Empresa Pública; y SANTESMASES, M.J. (2001), Entre Cajal y Ochoa. Ciencias biomédicas en la España de Franco, Madrid, CSIC, capítulo 4. 
gico de recluir a Jorge Federico Tello y a Fernando de Castro, y del mismo modo que Cajal procedía, como ha explicado muchas vez López Piñero, de una escuela micrográfica que ya sabía observar la microscopio, los trabajos en neurohistología y en neurofisiología que se empezaron a producir en España en los años 50 deberían relacionarse con la supervivencia y la vigencia de Cajal y de su obra ${ }^{24}$. Y así la memoria científica experimental se sumaba a la memoria institucional. No sólo se reciclaban los edificios, también pudo, pese a las depuraciones, recogerse lo que se había aprendido con los métodos y las ideas de Cajal sobre el funcionamiento del sistema nervioso.

Ochoa, por su parte, procedía de los laboratorios de la JAE, en donde aprendió junto a Negrín y se dejó guiar por sus ideas científicas y sobre la formación de jóvenes en el extranjero. Y aunque su trayectoria como investigador se consolida en los Estados Unidos a la sombra del apoyo que le proporcionó la poderosa, por influyente, Fundación Rockefeller, los orígenes de sus intereses y su formación científica primera se adquiere en España. Y cuando regresa a la vida pública de su país natal, no deja de recordar los trabajos y el reconocimiento científico de Cajal mientras apoya explícitamente a investigadores del área de su propia especialización, la bioquímica primero y más tarde la biología molecular. Incluso si las referencias de Ochoa a Cajal pudieran haber sido un recurso retórico, no deja de sugerir que un país con apoyos muy escasos a la investigación y al trabajo experimental, o algunos de sus investigadores vistos como colectivo, pudo haberse conservado - mantenido, recodificada en el nuevo medio de la posguerra mundial - la influencia de una tendencia a favor de las ciencias y la experimentación en España, con afanes productores de nuevos saberes y prácticas nuevas ${ }^{25}$.

Pese a ser reconocimientos independientes, con cincuenta años entre ambos, son cincuenta años que no transcurren en el vacío por más que quizá ese hubiera sido el interés de la retórica contra el positivismo de las autoridades en la inmediata posguerra. La práctica investigadora contaba a finales de la década de 1950 con unos modos de trabajo y algunas normas que articulaban una vida académica que, por modesta que fuera, puede tomarse como una organización, como algo más establecido que un laboratorio. Los inicios de los trabajos de laboratorio están marcados por medios muy escasos, apenas existentes. Las personas encargadas por Albareda de llevar a cabo trabajo

24 López Piñero, J. M. (2000), Cajal, Barcelona, Debate.

25 He sugerido algo similar en el último capítulo de SANTESMASES, M.J. (2001), Entre Cajal y Ochoa, op. cit. Sobre Ochoa, véase SANTESMASES, M.J. (2005), Ochoa: de músculos a proteinas, Madrid, Síntesis. 
experimental en los laboratorios del CSIC son al principio profesores de las universidades y a partir de 1945 empiezan a crearse puestos de trabajo científico propios del CSIC para licenciados y doctores más jóvenes. Los usos de la dictadura durante los años 40 no son los más estimulantes para la creatividad, cuando el miedo y la sospecha estaban instalados como articuladores de la vida civil. Esas normas duramente represoras de la dictadura dejarían su rastro en una comunidad que acudiría a su formación académica y a su especialización científica para quedar a salvo de los arrebatos del dictador y de sus métodos de control ideológico. Pero también las normas aplicadas por la JAE, no solo de formación científica en el extranjero sino también de valoración de méritos académicos y, lo que probablemente fue de influencia más duradera e intensa en el medio plazo, de hacer explícita la necesidad de cubrir carencias españolas por medio de aprendizaje en el extranjero, por medio de viajes, tuvieron su parte.

De esta forma, puede considerarse que las generaciones que a mediados de la década de 1950 entran en las universidades son un producto de ambos rastros, de influencia doble, cuyos elementos a veces pudieron quedar en conflicto: cómo protegerse de la dictadura y emprender una carrera académica e investigadora a la vez a menudo fue difícil, especialmente si se tiene en cuenta que las condiciones económicas de la investigación en España eran muy limitadas, más aun comparadas con la de los países a los que algunas personas jóvenes pudieron acudir a formarse ${ }^{26}$.

Las organizaciones recuerdan - sus gentes practican la memoria y esta memoria es agente de la historia-, como dice Mary Douglas (1986) que piensan las instituciones. Esas prácticas parecen haber quedado entre las normas y las trayectorias de la organización de la investigación, podrían haber traspasado fronteras temporales y políticas. El exilio de muchas gentes y la muerte de otras no hace desaparecer las ideas, tampoco aquellas que atañen a la formación y a la practica científicas ${ }^{27}$.

Los trayectos de las ideas científicas, de las prácticas experimentales e investigadoras, de las ciencias mismas tenían antecedentes inmediatos, como los habían tenido Santiago Ramón y Cajal, Luis Simarro y Nicolás Achúcarro. Los intereses por la bioquímica, por ejemplo, procedieron, como en otros países de la fisiología y de la química. El caso de la trayectoria científica de Alberto Sols lo ilustra bien: empieza usando músculos enteros en los años 40

26 Tusell, J. (1982), Franco y los católicos, Madrid, Alianza; Lizcano, P. (1981), La generación del 56. La Universidad contra Franco, Barcelona, Grijalbo.

27 Douglas, M. (1986), How Institutions Think, London, Routledge-Kegan Paul. 
y aprende a triturarlos y a extraer de ellos sustancias que identifica y cuya actividad es capaz de analizar entre finales de esa década y principios de la siguiente. De modo que cuando regresa a Madrid en 1953 y pretende crear un grupo de trabajo dedicado al estudio de los enzimas, encuentra inicialmente apoyos tímidos de las autoridades y pocos colegas que puedan acompañarle. A principios de los años 1960 su proyecto investigador tenía buen paso, aunque el reconocimiento que creía merecer solo le fue ofrecido a mediados de la década siguiente de $1970^{28}$.

\section{LAS INFLUENCIAS EXTRANJERAS}

Junto a eso, se introdujeron otras influencias además de las procedentes de los tiempos de la JAE, marcadas por el signo de los tiempos de la posguerra mundial. Los códigos investigadores de la JAE atravesaron las fronteras políticas y temporales que se levantaron entre la República y la dictadura de Franco.

Si durante el franquismo se nacionalizó la industria por falta de iniciativa privada o si esta se vio sofocada por el poder de un estado controlador y nacionalista es polémica que sigue viva. Acaso las ambiciones del estado y las de los industriales habrían entrado en conflicto durante la autarquía, disonancias que terminaron siempre a favor del estado, más poderoso, para resolverse estas cuando se estabilizó la influencia de la Europa aliada en la etapa de consolidación de las políticas nacionales e internacionales que surgen del fin de la segunda guerra mundial. Y se solventaron a favor de la compra sistemática de tecnología extranjera ${ }^{29}$. La retórica de la dictadura, de comerciantes, industriales y de al menos los grupos sociales más poderosos trasladó sus contenidos del apoyo al producto autóctono - un nacionalismo aislacionista - a la promoción de modernos productos extranjeros y de los acuerdos con empresas también extranjeras para comprar y aplicar aquí sus métodos de fabricación.

Y así la aversión al viaje de las autoridades de la dictadura - Franco viajó poco y muy contados y distinguidos diplomáticos tocados por su poder lograron desempeñar algún papel en las negociaciones en el extranjero cuando

28 SAntesmases, M.J. (1998), Alberto Sols, Alicante, Fundación Gil-Albert.

29 CEBrián, M. (2004), Technological Imitation and Economic Growth during the Golden Age in Spain: 1959-1973, tesis doctoral, Florencia, Instituto de la Universidad Europea; LóPEZ, S. and M. CEBRIÁN (2004), «Economic Growth, Technology Transfer, and Convergence in Spain, 1960-1973», en LJUNBERG, J. y J.-P. SMITS, eds., Technology and Human Capital in Historical Perspective, New York, Palgrave-Macmillan, pp. 120-144. 
terminó la Segunda Guerra Mundial — es comparable a la aversión a viajar a España de las autoridades aliadas vencedoras ${ }^{30}$. Pero igual que la victoria aliada no llegó a poner en riesgo la dictadura, tampoco esta llegó a impedir el ejercicio experimental pese a haberlo acusado de positivista irreverente ${ }^{31}$.

\section{LA EXPERIMENTACIÓN BIOLÓGICA Y MÉDICA}

Los laboratorios de la JAE generaron promesas que su política de ampliación de estudios en el extranjero contribuía a implantar. Las limitaciones de los medios económicos de la JAE se conocen bien. Comparada con los apoyos que disfrutaban algunos de los biólogos y experimentadores médicos de Alemania en ese momento, bajo el poderoso paraguas de la Sociedad Kaiser Wilhelm, era una institución modestísima. Pero la ambición era muy superior a los medios: si Negrín pidió que de su sueldo se gratificara a los colaboradores jóvenes, su gesto revela que él creía que debían ser retribuidos. Pero no basta con mirar a aquel momento concreto con mucho detalle histórico y documental para hacerse idea de las posibilidades que habría ofrecido en España un grupo de gente formada en métodos y ambiciones académicas y científicas como fue el que se dedicaba a la histología, a la fisiología y a la biología en los distintos laboratorios de la JAE. Acaso en ese momento la situación de la investigación científica y experimental haya estado más cerca de lo que ocurría en los centros que se dedicaban a ello en el entorno geográfico y político de España de lo que lo había estado nunca hasta entonces, y más de lo que llegaría a estarlo después. Puede recordarse, lo que sería un refuerzo de esta hipótesis, la influencia que desplegaron muchos de los que de allí se exiliaron en los países donde se instalaron en la América Latina. Francisco Giral (1994) ha hecho listas largas cuando ya la literatura sobre el exilio era extensa ${ }^{32}$. Y con ocasión del Nobel a Ochoa, otros recordaron el ambiente de los lugares en los que habían comenzado su formación y su carrera académica. Creo que esos

30 Los viajes originaban líneas de trabajo: véase ROMERo DE PABLOS, A. (2000), «Un viaje de José María Otero Navascués. Los inicios de la investigación de la energía nuclear en España», Arbor, 167 (659-660), 509-526.

31 GonZÁlez BLASCO (1980) y SÁNCHEZ Ron (1999)

32 GIRAL, F. (1994), Ciencia española en el exilio(1939-1989): el exilio de los científicos españoles, Barcelona-Madrid, Anthropos-Centro de Estudios Republicanos. Véase también GARCÍA CAMARERo, E. (1978), «La ciencia española en el exilio de 1939». En Abellán, J.L. (dir.), El exilio español de 1930, Madrid, Taurus, pp. 189-243. 
recuerdos, las nostalgias que manifestaron, deben considerarse expresión de la memoria, no solo de lo que tenían sino el rastro, la influencia que recibieron y que tenía relación con aquello en lo que se habían convertido, decisiones propias e influencias recibidas testimoniarían de esta manera sus efectos.

Todo lo cual tuvo manifestaciones directas en las formas de enseñar y practicar la investigación biológica y médica. Tras las depuraciones dramáticas o, mejor dicho, durante la década larga que duraron los procedimientos de estudio de las actividades y declaraciones de los funcionarios públicos, parece haberse difundido una retórica por la investigación. Desde los primeros años de existencia del CSIC Franco presidía reuniones anuales, además de elogiar y premiar la producción - aunque fuera valorada al peso, como diría el fisiólogo Antonio Gallego-, lo que puede considerarse testimonio de un interés por las ciencias y la investigación. Y muy poco a poco aquellos edificios, unos procedentes del patrimonio de la JAE, otro reciclados por Miguel Fisac y otros diseñados por él, además de todas las obras ejecutadas para el CSIC en plena década del hambre, fueron ocupados por la experimentación.

Mientras tanto, algunos profesores purgados y sin sanción empezaron a viajar al extranjero: los becados por la Junta de Relaciones Culturales del Ministerio de Asuntos Exteriores establecían contacto con un sacerdote a través del cual las autoridades sabían del correcto discurrir de su estancia extranjera. Con el fin de la segunda guerra mundial, Estados Unidos fue uno de los destinos principales y el número de becas y bolsas de viaje - el término pensión parece haber sido borrado de la faz de la península - fue aumentando ${ }^{33}$.

Ese destino americano se hizo famoso y, más tarde, para algunos políticos y científicos, imprescindible; no sólo por las ayudas a viajes que ese mismo país ofreció desde la inmediata posguerra, sino también porque allí acabaron los huesos de los científicos europeos vivos más productivos de toda la Europa que había construido en pleno periodo de entreguerras el conocimiento.

A Estados Unidos emigraron apoyados por programas privados algunos de los más selectos de entre los de más edad y muchos de los más jóvenes prometedores por la formación que habían recibido junto a aquellos que terminaron por emigrar también. Esa parte de la diáspora judía que superó, o desdeñó, el antisemitismo estadounidense construyó, o contribuyó a construir, una comunidad científica que resultó ser después de las más poderosas de Occi-

33 Un estudio de las becas españolas para ampliar Estudios en Estados Unidos, especialmente a partir de los años 1960 está en DELGADO, L. (2005), «Cooperación cultural y científica en clave política, En Delgado, L., y Elizalde, M. D. (eds.), España y Estados Unidos en el siglo $X X$, Madrid, CSIC, pp. 207-243. 
dente. Lo que se obtuvo tras trasladar, o facilitar el traslado, de los más insignes de entre los de mediana edad, y proveerlos de presupuestos que no harían más que crecer hasta la crisis del petróleo fueron los éxitos sonados de los que en la década de 1960 se denominó biomedicina ${ }^{34}$.

Mientras Severo Ochoa lograba reconocimientos crecientes en su país de adopción, instalado en el corazón de Manhattan, iban poblándose lentamente los laboratorios construidos en el interior de edificios pretenciosos y modernos que eran los del CSIC. Los restos de la escuela de Santiago Ramón y Cajal fueron completamente alcanzados por la purga depuradora de las nuevas autoridades. Sobrevivieron a ella, con una consulta privada Jorge Federico Tello; en un laboratorio casi vació y exento de apoyos, Fernando de Castro; y otros terminaron por hacerse hueco en las nuevas normas y en sus estructuras académicas, como Julián Sanz Ibáñez y José María del Corral ${ }^{35}$.

Pero, ya se ha dicho, el viaje de jóvenes dispuestos a completar su formación científica no llegó a detenerse por completo nunca. De los escombros de la Ciudad Universitaria y sus jerarquías académicas depurantes - muchos decanos estuvieron al frente de las comisiones encargadas del destino de sus colegas - surgieron bioquímicos modestos cuyos estudiantes viajaron. Cuando murió Antonio de Gregorio Rocasolano, uno de los maestros de la principal autoridad del CSIC, se puso su nombre al que se había llamado edificio Rockefeller y la memoria histórica ha mantenido su nombre para denominar a uno de los edificios más antiguos de la extinta JAE, de manera que la vida cotidiana del organismo público de investigación de mayores dimensiones de España parece vivir sin esa memoria ${ }^{36}$. De aquel edificio prosperaron científicos importantes pero no fue hasta los años 60 cuando emergieron los grupos en los que se iniciaron las carreras investigadoras de algunos de los científicos que destacarían después, hombres y mujeres cuya fama se celebra hoy. La

34 Sobre los científicos europeos dedicados a la biología y a la biomedicina emigrados, o cuya emigración fue apoyada, en este caso por la Fundación Rockefeller, véanse los estudios críticos de WeIndling, P. (1999), «The Rockefeller Foundation and German biomedical scientists 1920-1940): from educational philanthropy to international science policy», en GEMELLI, G., J.-F. PICARD y W. H. SCHNEIDER (eds.)(1999), Managing medical research in Europe. The role of the Rockefeller Foundation (1920s-1950s), Bologna, CLUEB, pp. 117-135, e íbid, (2000), «An overloaded ark? The Rockefeller Foundation and the refugee medical scientists», Studies in History and Philosophy of Biological and Biomedical Sciences 31, 477-489.

35 Sobre la depuración de los discípulos y colaboradores de Cajal, véase SANTESMASES (1998).

36 Sobre Rocasolano véase Cebollada, J. L. (1988), «Antonio de Gregorio Rocasolano y la escuela química de Zaragoza», Llull, 11, 189-216. 
mayoría, si no la totalidad, de los intereses construidos en aquellos años procede más de la influencia extranjera que de las herencias directas de lo más valioso de la $\mathrm{JAE}^{37}$. Eso comparte la investigación española de aquel tiempo con otros sectores profesionales. La intensidad de la influencia extranjera comienza en los años 50 y eso se ve también con mucha claridad en los trabajos sobre los cambios de la propaganda en la posguerra ${ }^{38}$. Del ensalce de lo nacional se pasa a americanización, que tan directamente procedente de los Estados Unidos se detectó y se nombró en Francia de esa forma, americanización, en plena posguerra mundial.

\section{PARA CONCLUIR}

Con la muerte de Franco y a lo largo del proceso de democratización de España comenzaron a recuperarse la memoria de la JAE y su valor en el medio plazo. Eso sería otra historia que consistiría en la propia historiografía de la JAE. Quizá solo ahora, cien años después de su creación, y con el peso de la historiografía tanto como de la historia podamos regresar a recoger el poso que ha dejado en las normas y en los códigos de la comunidad científica española, que en pleno siglo XXI no podría ya renunciar a reconocerse como un producto tanto del desarrollo científico extranjero como del rastro de la primera institucional estatal que promovió la formación de investigadores y la experimentación en la España contemporánea. Aunque no haya sido la única influencia, sí fue, de entre las españolas, la que ha dejado rastro duradero tanto en la memoria institucional como en la historiografía. Los viajes, emprendidos por gentes pensionadas, por proyectos, ideas y prácticas experimentales, están en el corazón de esa influencia.

37 Véase el ambiente científico en la España de la posguerra y la importancia de las relaciones extranjeras desde el fin de la Segunda Guerra Mundial en MALET, A. (1995) Ferran Sunyer i Balaguer (1912-1967), Barcelona, Institut d'Estudis Catalans.

38 SueIro, S. (2007), «La posguerra en imágenes», en SueIro, S (ed.), Posguerra, publicidad y propaganda (1939-1959), Madrid, Sociedad Estatal de Conmemoraciones CulturalesCírculo de Bellas Artes, pp. 13-295. 